\title{
Influence of Information Technology Revolution on Insurance Industry in New Century
}

\author{
N. Sabitha Devi , Vedulla Shekhar \\ ${ }^{1}$ Research Scholar, Department of Business Management, Osmania University, Hyderabad \\ ${ }^{2}$ Professor, Department of Business Management, Osmania University, Hyderabad \\ sabithadevi.23@gmail.com
}

\begin{abstract}
The insurance companies are becoming aware that thanks to the business environment which is becoming more and more competitive nowadays, their priority should be the control over the ultimate market. That means holding good relationship with customers. Companies can get feedback of what customers are trying to find by understanding them better, their choices, preferences and what they expect and what they need from company's product or services offered. The advance in Information Technology offer new ways of managing relationship. In this paper an attempt has been made to give a better understanding with regard to Insurance Industry issues and challenges in this new century, methods to overcome these challenges and Insurance Technology trends transforming the industry in this new era and finally presents conclusions based on the study.
\end{abstract}

Keywords: Insurance Industry, Issues, Challenges and Insurance Technology Trends.

\section{Introduction}

In the past few decades there has been a revolution in computing and communications, and every one indication are that technological progress and use of data technology will continue at a rapid pace. Accompanying and supporting the dramatic increases within the power and use of latest information technologies has been the declining cost of communications as a results of both technological improvements and increased competition. According to Moore's law the processing power of microchips is doubling every 18 months. These advances present many significant opportunities but also pose major challenges. Today, innovations in information technology are having wideranging effects across numerous domains of society, and policy makers are acting on issues involving economic productivity, intellectual property rights, privacy protection, and aordability of and access to information. Choices made now will have long lasting consequences, and a spotlight must be paid to their social and economic impacts.

The insurance companies are becoming aware that thanks to the business environment which is becoming more and more competitive nowadays, their priority should be the control over the ultimate market. That means holding good relationship with customers. Companies can get feedback of what customers are trying to find by understanding them better, their choices, preferences and what they expect and what they need from company's product or services offered. The advance in Information Technology offer new ways of managing relationship.

\subsection{Objectives of the Study}

The main objectives of this paper are:

- To discuss the Insurance Industry Issues in new century

- To brief out the biggest challenges for Insurers

- To focus on the methods to overcome these challenges

- To present the Insurance Technology trends transforming the Industry in new century

\subsection{Research Design}

The details of research design of this paper were as follows:

\subsection{Data collection}

The secondary data is collected for the purpose of study.

\subsection{Sources of Data}

The data has been collected from different sources like Web sites of IRDA, Journals, Magazines, Newspaper, articles etc.

\subsection{Insurance Industry Issues in New Century}

Industry transformation is taking change from threat to opportunities by using Information Technology. Comfort levels rising with new insurance technologies and strategies. While generational change remains buffeting the insurance industry, many insurers are getting easier with new technologies and changing from product-focused to customer-centric organizations. They are increasingly hospitable forming partnerships with InsurTechs and using technology and new ways of thinking to streamline operations, better serve customers and augment a changing workforce. In addition, prescient companies are using changes to industry standards (most notably LDTI within the US and IFRS 17 elsewhere) as a catalyst to implement many of those strategic and operational changes, also as determine viable business strategies for the longer term. Insurance issues explored are:

\section{a) Digitizing small commercial}

Because small commercial insurance may be a large and profitable marketplace for those that know it, it's now attracting an excellent batch of attention-and is struggling to modernize. As a result, carriers are finally making significant investments in the digital space. 
b) Improving the customer experience with data analytics

Insurers' increasing access to customer data, analytical tools and marketing technology is enabling outreach to customers and a transparent line of sight into what resonates with them. Carriers are increasingly able to quantify the pain points that cause a customer to leave - a true moment of truth - and use this data to improve the customer experience.

c) Driving change with InsurTech

Reflecting a growing maturity linking technology and strategy, new and existing players are increasingly that specialize in distribution channels and the way carriers interact with policyholders and employees so as to make a beautiful, brand differentiating experience.

d) Getting value from the digital journey

Whether you're embarking on a digital transformation or just making targeted improvements, there are a few important things to keep in mind to get value from the digital journey.

e) Insights from experience design

As carriers try new ways of doing business, one among the most important developments at the company level is experience design owning a seat at the table, due to its vital role within the customer experience and brand architecture.

f) Model risk management 2.0

MRM 2.0 is evolving as a results of revisiting the definition of "model," a shift to validating new models, rationalizing the three lines of defense and seeking cost efficiencies.

g) LDTI and IFRS 17 implementation synergies

Because both FASB LDTI and therefore the IASB IFRS 17 approaches address similar considerations, companies that require to dual-adopt are finding opportunities for synergies as they refine their approach to implementation. They'll be ready to align policy decisions while simultaneously adopting both standards without having to stress about two full implementation plans.

h) Impacts of the Tax Cuts and Jobs Act

The Tax Cuts and Jobs Act's provisions have had impacts on insurers' operations and business decisions that go far beyond tax. We highlight the Act's most salient effects on insurers, also as provide perspective on extensive IRS and Department of the Treasury guidance under the Act.

\section{Embracing digital transformation: The 5 biggest} challenges for insurers

Executives expect technology to help them improve their competitiveness and customer loyalty while cutting costs and boosting growth. But to achieve a successful digital agenda, there are several hurdles insurers need to surpass. Here are the top five digital optimization and transformation challenges for insurers in this new century.

\section{1) Grow Business Through Great Experiences}

In a competitive market such as insurance, where the performance of agents and brokers is critical for acquiring new customers and keeping existing ones, executives have a new mandate: optimize the experiences of their teams. Easy-to-use and friendly portals must be at the top of their agendas.

2) Speed Time-to-Market and Beat Insurtech Competitors

Insurtech has shaken up the insurance business. Taking advantage of data analysis and new technology like GPS car tracking or the activity trackers on wearables, Insurtech has transformed the market with new solutions and better experiences. And, even though the startup activity in insurance has slowed, Insurtech continues to play a major role in shaping the future of the industry. The biggest challenge for traditional insurers is to align their years of experience-something Insurtech companies lack - with new ways of reaching customers, policyholders, agents, and partners. And, of course, do it all with speed, agility, and the right time to market.

3) Deliver Seamless Experiences across Countries

As most insurance carriers operate across different states and even countries, companies need to ensure they deliver a seamless experience. But different countries have different regulations, and insurers need to adapt their policies and procedures to be compliant everywhere. Not to mention that those regulations are getting tighter and tighter. Last year, the European Union updated the Insurance Distribution Directive. And in 2016, the U. S. government expanded the Department of Labor Fiduciary Rule to add stricter governance on how an advisor deals with a client in 2017. Although a Court of Appeals vacated the rule in 2018 , insurers had already put measures in place to comply. In addition, the SEC is looking at it closely and might implement parts of it in new century. The challenge for insurance companies that operate in a multitude of countries is to be able to customize and adapt their business and user experiences quickly to comply with the different federal or state policies.

4) Ensure a Connected Digital Ecosystem

As competition continues to increase, many larger insurers are growing their business and services offerings by plugging other companies into their ecosystem. For example, "Pay-As-You-Go" insurance is an auto insurance program that adjusts rates based on the number of miles you drive. As a result, they're able to broaden their market to new customers, diversifying their product and services portfolio. But it also makes their business a lot more complex. Insurers must connect all these different components of their ecosystem seamlessly, ensuring a smooth experience for customers, brokers, agents, and partners.

5) Maintain Legacy Systems and Address the Increasing Backlog

As we mentioned, innovation is essential for insurers to stay competitive. However, the results can take some time, which can become frustrating. Many companies, especially mature ones, still trust their business to complex, disjointed legacy systems that consume not only financial but also human resources, hampering innovation. At the same time, their backlog continues to grow. According to the State of Application Development, Insurance Industry Report, 65 percent of IT professionals said they have an app dev backlog, and for 10 percent of these respondents, the backlog was 
over 10 apps. Only 32 percent said their app dev backlog had improved in the last year. In addition, according to the same report, development skills are hard to find: 65 percent of organizations have hired web or mobile developers in the past year. Eighty percent of respondents described app dev talent as scarce, with hiring taking longer and costing more.

\section{Methods to Overcome these Challenges}

The question is: is digital transformation an opportunity or a threat? It's all a matter of adaptability, really. Forwardthinking companies will look at these challenges as an opportunity to differentiate themselves from their competition. And that's where low-code can help you.

Insurance companies like Liberty, AXA, Fidelidade, and Zurich have been using the Out Systems low-code platform to deliver next-generation agent portals and customer experience capabilities. The result is better engagement and communication with their agents and customers across any channel or device.

With Out Systems we can:

- Increase your time to value: Build customer and agent portals up to 10 times faster than your competition.

- Enhance your IT team's agility: Customize and configure applications based on customer or agent feedback or adhere to new regulation standards within a matter of hours.

- Break down silos: Knock down all the siloed legacy systems and orchestrate all data streams into a single viewpoint and achieve the holy grail of a 360-view of the customer using the OutSystems API layer.

- Improve your flexibility: Build a customer portal or rewrite a core legacy system. OutSystems is a highly flexible platform that grows and flexes with your business.

- Write and reuse: Reduce the need to rebuild and save time and development resources by reusing "objects" across applications that require the same piece of functionality.

\section{Insurance technology trends transforming the industry} in new century

Advanced insurance technology is already an integral part of the P\&C industry, for both carriers and insureds. Getting insurance quotes are often as easy as clicking a button, managing coverage can typically be accomplished via a mobile app, and paper insurance cards are mostly a thing of the past.

Insurance technology is poised to mature even more in present scenario. While a number of these tools are already employed by some carriers, we see them becoming more and more commonplace throughout the industry. Insurers trying to find a competitive edge should consider embracing one or more of those eight emerging insurance tech trends.

\section{1) Artificial Intelligence (AI)}

Consumers are always looking for personalized experiences, especially when purchasing something as important as P\&C insurance. AI offers insurers the power to make these unique experiences, meeting the high-speed demands of recent consumers. With AI, insurers can improve claims turnaround cycles and fundamentally change the underwriting process. AI also enables insurers to access data faster, and cutting out the human element can lead to more accurate reporting in shorter periods of time. A report from PwC forecasted that AI's initial impact will primarily relate to improving efficiencies and automating existing customerfacing underwriting and claims processes. Over time, its impact will be more profound; it can identify, assess, and underwrite emerging risks and identify new revenue sources.

\section{2) Machine Learning}

Insurance technology trends will include the overlapping of varied technologies, beat the name of improving accuracy. According to Forbes, "Machine learning is technically a branch of AI, but it's more specific ... Machine learning is predicated on the thought that we will build machines to process data and learn on their own, without our constant supervision."

Machine learning can't only improve claims processing, it can automate it. When files are digital and accessible via the cloud, they will be analyzed using pre-programmed algorithms, improving processing speed and accuracy. This automated review can impact quite just claims - it are often used for policy administration and risk assessment.

\section{3) IoT (Internet of Things)}

Most consumers are willing to share extra personal information if it means saving money on their insurance policies - and therefore the Internet of Things (IoT) can automate much of that data sharing. Insurers can use data from IoT devices like the varied components of smart homes and wearable technologies to raised determine rates, mitigate risk, and even prevent losses in the first place. IoT will bolster other insurance technology with first-hand data, improving the accuracy of risk assessment and giving insureds more power to directly impact their policy pricing.

\section{4) Social Media Data}

Social media and its role within the insurance industry is evolving beyond marketing strategies and clever advertisements. Mining social media data is improving risk assessment for P\&C insurers, bolstering fraud detection capabilities, and enabling entirely new customer experiences. Insurance technology also can leverage social media to research fraud. Insurers can look at the social activity of insured's and compare it to claims records, looking for any discrepancies. A Morgan Stanley report cited a tool utilized by carriers to research claims throughout the assessment process that examines the social relationships between parties involved - and monitors their activity on the day of the loss to seem for red flags.

\section{5) Telematics}

Auto policies will still be impacted by telematics capabilities. In insurance technology, consider telematics as wearable technology for your car. Cars equipped with monitoring devices - think Progressive's Snapshot measure various indicators such as data on speed, location, accidents, and more, which is all monitored and processed with analytics software to determine your policy premium. 
The benefits of telematics are numerous for both insurers and insureds. Telematics in P\&C insurance will:

- Encourage better driving habits

- Lower claims costs for insurers

- Change carrier to customer relationships from reactive to proactive

\section{6) Chatbots}

By some estimates, by $202595 \%$ of all customer interactions are going to be powered by chatbots. Utilizing $\mathrm{AI}$ and machine learning, chatbots can interact with customers seamlessly, saving everyone within a corporation time - and ultimately saving insurance companies money. A bot can walk a customer through a policy application or claims process, reserving human intervention for more complex cases. Geico's "Kate" may be a virtual assistant that communicates with customers via text or voice, aiding in policy questions and coverage inquiries, available 24/7. More insurance companies are investing in technology like this, and chatbot capabilities are expected to extend in 2019.

\section{7) Drones}

Insurers are taking to the sky, or a minimum of their drones are. Unmanned drones are an insurance technology tool that will be utilized more by carriers in this era. They can be used across many stages of the insurance lifeycle collecting data to calculate risk before issuing a policy, aiding in preventative maintenance, and assessing damage following a loss. Farmers insurance may be a great example, as they deploy Kespry drones to assist risk and damage assessment on homes. These drones perform roof inspections and other assessments, and therefore the drones transmit their data to the cloud for analysis. This is yet one more instance of IoT and other technologies working together within the insurance industry.

\section{8) Predictive Analytics}

Predictive analytics is employed by many insurers to gather a spread of knowledge to know and predict customer behaviour. However, there are new ways it are often utilized to enhance accuracy of knowledge.

Insurance companies can use predictive analytics for:

- Pricing and risk selection

- Identifying customers at risk of cancellation

- Identifying risk of fraud

- Triaging claims

- Identifying outlier claims

- Anticipating trends

\section{Conclusion}

Emerging technologies and innovations are beginning to transform the insurance landscape as they enable new ways to measure, control, and price risk, engage with customers, reduce cost, improve efficiency, and expand insurability. This has produced enormous opportunities for established insurers to modernize create new insurance products and services, and shake up their business models. At the same time, addressing issues surrounding comprehensive data regulation will grow in importance, and insurance regulators and data privacy rules will play a significant role in determining how insurers will be able to use data and also influence the level of product customization available to customers. With all of the innovation going to market in recent years, from smart home technology to insurtechs and microservices, the upcoming year will be a very interesting year to watch for insurance technology developments.

\section{References}

[1] Tyagi C. L. \&MadhuTyagi (2007) - Insurance: Law and Practice - Atlandit Publishers \& Distributors, New Delhi

[2] TapenSinha (2009)-The Indian insurance industry: Challenges And Prospects

[3] Niladri Das (2008)-Services marketing in the new global era: a case study of LIC International Journal of Business and Globalization-Vol.2, No.3 pp.300 - 309

[4] D. Chennappa (2007) - Insurance sector Reforms in India: Challenges and Opportunities - Karshak Art Printers, Hyderabad

[5] Kumar N. S. (2009) - Management of Financial Institution and Market - Allahabad Law agency, Faridabad

[6] Sabera K (2007). Changes in insurance sector-A Study on Public Awareness-J. Insurance Chronicle 7 (1): 37.)

[7] S. Krishnamurthy (2005) - Insurance Sector: Challenges of Competition and Future Scenario Vikalpa, Vol-30, No.-3

[8] www.outsystems. com

[9] www.pwc. com 